\title{
Utilization of an ESEMTM with an Embedded Heating Stage to Investigate Pyrolosis in Immature Oil Shale
}

\author{
Marc Castagna ${ }^{1}$, Eric Goergen ${ }^{1}$, Kimbal Skinner ${ }^{1}$ and Jeremy E. Dahl ${ }^{2}$ \\ ${ }^{1 .}$ FEI Company, Hillsboro, Oregon. \\ 2. Stanford Institute for Materials and Energy Sciences, Stanford University, Stanford.
}

The environmental scanning electron microscope (ESEM) is utilized for various geologic applications as it is well suited for dealing with the charging problems of uncoated specimens[1], the often wet nature of specimens, and the hydrocarbon contamination when interacting with geologic specimens[2]. The ESEM allows for many different dynamic experiments as well. By integrating a heating stage into the ESEM, carefully controlled heating profiles can be achieved while also allowing for direct observation of the material being heated. It is shown here that heating immature oil shale can be beneficial to understanding the process of converting hydrocarbons to gas and oil.

An ESEM with an embedded heating stage was utilized for these experiments. The integrated heating stage can be pre-programed based on ramp rate $\left({ }^{\circ} \mathrm{C} / \mathrm{min}\right)$ and target temperature, including soaking times to allow for equilibrium of the sample. The heating stage used was capable of heating the sample to $1000^{\circ} \mathrm{C}$. A near constant pressure of 50pa of forming gas was maintained in the chamber of the ESEM. In order to achieve greater sample stability, the specimen was adhered to a carbon crucible with high temperature ceramic glue. Imaging was performed with a specialized gaseous secondary electron detector (GSED) mounted on ceramic temperature isolation for the protection of the ESEM pole piece.

The experiment performed consisted of heating up a section of the rock to temperatures which should cause pyrolosis. The specimen examined was Kimmeridge source rock as described by Fishman[3]. It is observed that carbon rich material was released during the experiment. Figure 1 shows the top of the heating stage before (Figure 1A) and after (Figure 1B) the heating experiment. Direct before (Figure $2 \mathrm{~A}$ ) and after (Figure 2B) images are captured to show the effects of heating the shale. A time lapse movie of the entire heating process was generated by capturing images automatically throughout the heating experiment. This movie allows the observation of subtle changes in the microstructure of the specimen as it is heated. The images clearly show that the organic rich regions were significantly depleted during the experiment. This direct visualization suggests correlation of the temperature effects on the shale with other experimental observations [4].

\section{References:}

[1] GD Danilatos, Scanning Microscopy 4 (1990) p.799

[2] Magnus Ivarsson and Sara Holmström (2012). The Use of ESEM in Geobiology, Scanning Electron Microscopy, Dr. Viacheslav Kazmiruk (Ed.), ISBN: 978-953-51-0092-8 Chapter 39.

[3] Fishman, N.S., et al., The nature of porosity in organic-rich mudstones of the Upper Jurassic Kimmeridge Clay Formation, North Sea, offshore United Kingdom, Int. J. Coal Geol. (2012)

[4] TI Eddington, RP Philip, SJ Rowland, Organic Geochemistry 12 (1988) p. 33 

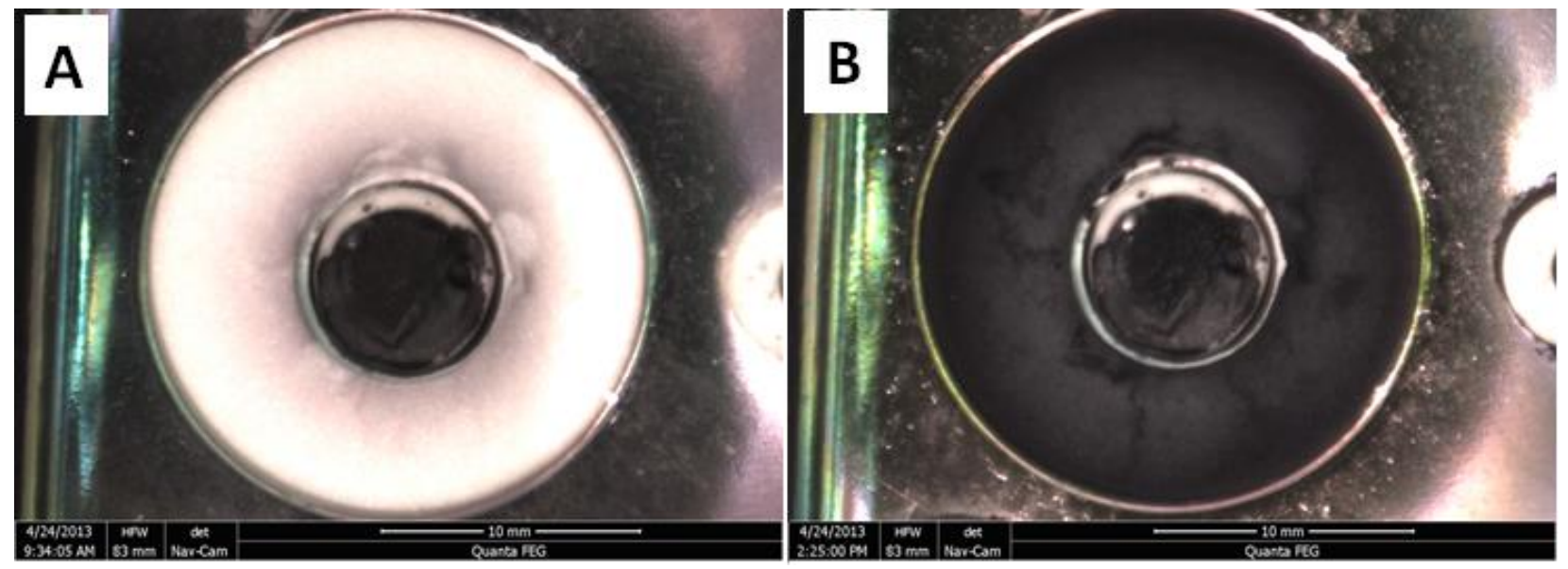

Figure $1 \mathrm{~A}$ and $B$

Figure 1. A. Top down view of heating stage before heating experiment and B. top down view of heating stage after experiment. Note the significant darkening of the insulating portion of the heating stage.
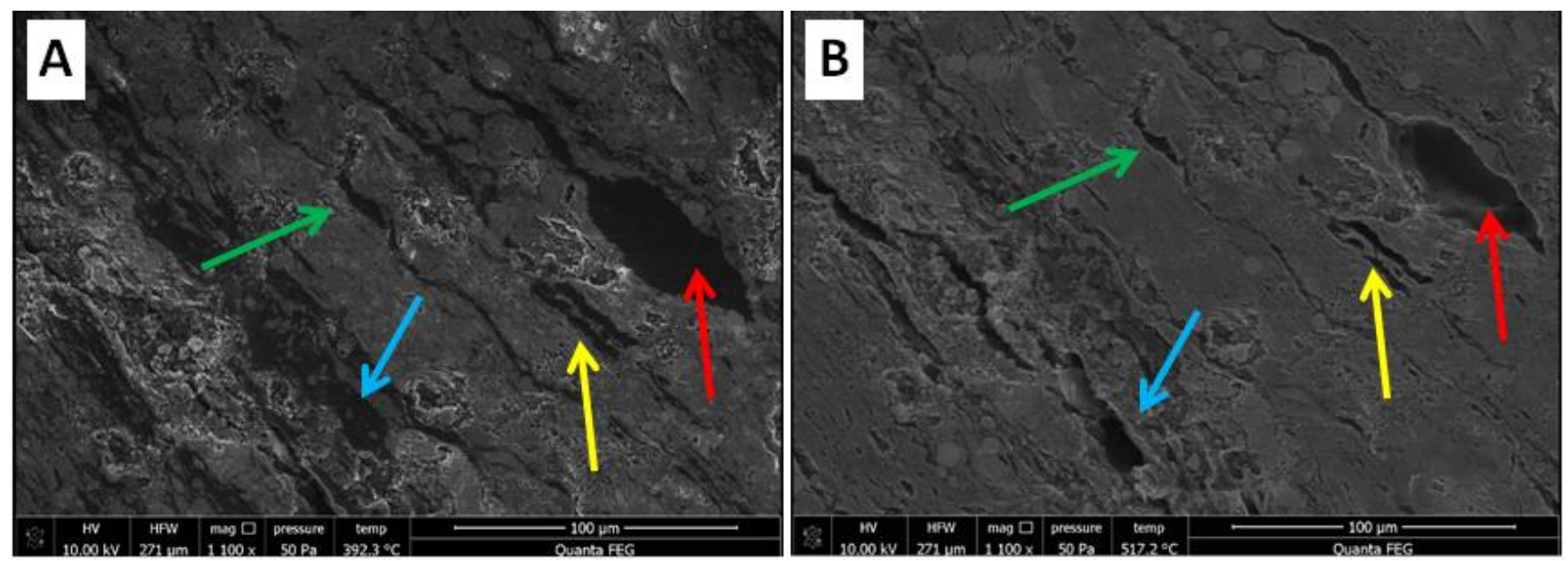

Figure $2 \mathrm{~A}$ and $\mathrm{B}$

Figure 2. A. Micrograph in the ESEM at $392^{\circ} \mathrm{C}$ and $\mathrm{B}$. at $517^{\circ} \mathrm{C}$ with markers showing the corresponding location at each temperature. 